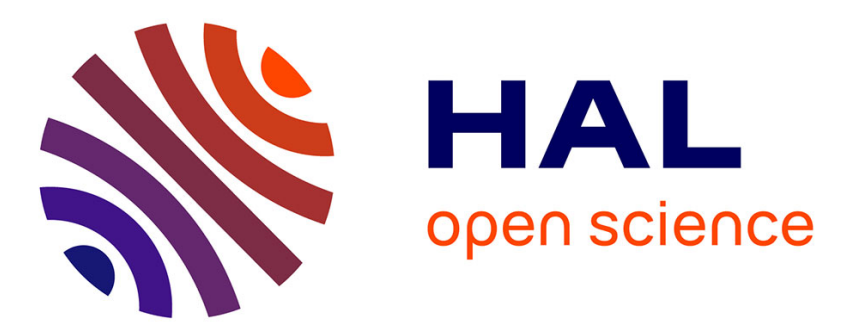

\title{
The funny current in genetically modified mice
}

Mattia Difrancesco, Pietro Mesirca, Isabelle Bidaud, Dirk Isbrandt, Matteo

Mangoni

\section{To cite this version:}

Mattia Difrancesco, Pietro Mesirca, Isabelle Bidaud, Dirk Isbrandt, Matteo Mangoni. The funny current in genetically modified mice. Progress in Biophysics and Molecular Biology, 2021, 166, pp.3950. 10.1016/j.pbiomolbio.2021.06.003 . hal-03437498

\section{HAL Id: hal-03437498 \\ https://hal.science/hal-03437498}

Submitted on 20 Nov 2021

HAL is a multi-disciplinary open access archive for the deposit and dissemination of scientific research documents, whether they are published or not. The documents may come from teaching and research institutions in France or abroad, or from public or private research centers.
L'archive ouverte pluridisciplinaire HAL, est destinée au dépôt et à la diffusion de documents scientifiques de niveau recherche, publiés ou non, émanant des établissements d'enseignement et de recherche français ou étrangers, des laboratoires publics ou privés. 
$4 \quad{ }^{1-4}$ Mattia L. DiFrancesco*, ${ }^{3,4}$ Pietro Mesirca, ${ }^{3,4}$ Isabelle Bidaud, ${ }^{5,6}$ Dirk Isbrandt ${ }^{3,4}$ Matteo E. Mangoni*

* corresponding authors

1) Center for Synaptic Neuroscience and Technology, Istituto Italiano di Tecnologia, Genoa, Italy

3) Institut de Génomique Fonctionnelle, Université de Montpellier, CNRS, INSERM, Montpellier,

Keywords:

21 Funny current, cardiac pacemaker activity, conduction system, sinoatrial node, genetically modified mice, rhythmogenesis 
2 Since its first description in 1979, the hyperpolarization-activated funny current $\left(I_{f}\right)$ has been the 3 object of intensive research aimed at understanding its role in cardiac pacemaker activity and its 4 modulation by the sympathetic and parasympathetic branches of the autonomic nervous system. $I_{f}$ 5 was described in isolated tissue strips of the rabbit sinoatrial node using the double-electrode voltage6 clamp technique. Since then, the rabbit has been the principal animal model for studying pacemaker 7 activity and $I_{f}$ for more than 20 years. In 2001, the first study describing the electrophysiological 8 properties of mouse sinoatrial pacemaker myocytes and those of $I_{f}$ was published. It was soon 9 followed by the description of murine myocytes of the atrioventricular node and the Purkinje fibres. 10 The sinoatrial node of genetically modified mice has become a very popular model for studying the 11 mechanisms of cardiac pacemaker activity. This field of research benefits from the impressive 12 advancement of in-vivo exploration techniques of physiological parameters, imaging, genetics, and 13 large-scale genomic approaches. The present review discusses the influence of mouse genetics based 14 on the most recent knowledge of the funny current's role in the physiology and pathophysiology of 15 cardiac pacemaker activity. Genetically modified mice have provided important insights into the role 16 of $I_{f}$ in determining intrinsic automaticity in vivo and in myocytes of the conduction system. In 17 addition, gene targeting of $\mathrm{f}-(\mathrm{HCN})$ channel isoforms have contributed to elucidating the current's 18 role in the regulation of heart rate by the parasympathetic nervous system. This review is dedicated 19 to Dario DiFrancesco on his retirement. 


\section{Introduction}

Historical perspective specimens of sinoatrial node (SAN) were extracted by hand from a rabbit heart using a delicate procedure that was based on cutting and silk-ligaturing 300- $\mu \mathrm{M}$-thick tissue strips and voltage clamping under a stereoscopic microscope using the two-microelectrode technique (Noma and Irisawa, 1976).

The size of the rabbit heart was appropriate for this demanding procedure. Sinoatrial node

The funny $\left(I_{f}\right)$ current was first described in 1979 (Brown et al., 1979) in a study in which tiny strips were just large enough for manual ligaturing under a microscope, and ligatured specimens were just small enough for satisfactory voltage control during two-electrode voltage clamp.

These combined features made the rabbit SAN the first, and, for several years, the only mammalian pacemaker tissue to be available for voltage clamp. It was only in the mid-eighties, when methods for enzymatic cell isolation were developed, that the Nobel Prize-winning patch-clamp technique allowed single pacemaker cells to be studied (DiFrancesco, 1986).

Even after the advent of enzymatic cell isolation techniques, the isolation of single pacemaker cells from rabbit nodal tissue remained the method of choice for investigating the funny current for several years before the first recordings of $\mathrm{I}_{\mathrm{f}}$ in mouse pacemaker myocytes were performed (Mangoni and Nargeot, 2001). Many relevant basic If properties originally described in multicellular SAN preparations and used in numerical modelling (see Noble 2021 in this issue) (Noble, 2020), were then confirmed in single-cell studies in rabbit SAN myocytes (DiFrancesco, 1986).

In parallel with the rapidly advancing investigation of cardiac electrical activity thanks to the exploitation of the new cell isolation and patch-clamp techniques, including single ion-channel recordings, methods designed to investigate molecular properties of ion channels became available. DNA sequencing, recombinant DNA, and heterologous expression techniques allowed much deeper insights to be gained into ion channel properties than was previously possible. In 1986, the first cloning, sequencing, and functional expression of sodium channels (Noda et al., 1986) opened new perspectives with respect to the acquisition of a more detailed knowledge of the molecular features of ion channels and their structure-function relationships.

Many subsequent studies benefited from the research efforts to unravel the molecular features of ion channels resulting in the cloning and sequencing of several voltage-dependent $\mathrm{Na}^{+}, \mathrm{Ca}^{2+}$, and $\mathrm{K}^{+}$potassium channels. The interested reader may want to read the book by Frances M. Ashcroft, Ion 
1 Channels and Disease (Ashcroft, 2001) on this historical topic. Funny channels lagged behind in this race, probably because of a more limited general interest, or simply because of their intrinsic complexity, and were not cloned until the late nineties from mouse brain, sea urchin sperm, and heart tissues (Gauss et al., 1998; Ludwig et al., 1998; Santoro et al., 1998; Vaccari et al., 1999).

Cloning of HCN1-4, the four molecular correlates of the pore-forming subunits of funny channels, was the missing step in the advancement of molecular investigations and genetic manipulation of these channels. The time was ripe for the development of a new animal model that was more suitable for the genetic investigation of funny/HCN channels than the rabbit model.

The funny current in mouse pacemaker myocytes

Since its first description, the role of the funny current in the genesis and regulation of cardiac automaticity has been under constant debate. A part of this debate is rooted in the methodological approaches used to study SAN pacemaking. Indeed, until the late nineties, the importance of ionic currents in cardiac pacemaking was generally assessed using ionic or organic blockers. Although this approach was appropriate, the limited selectivity of these blockers or agonists, under physiological conditions of cyclical variation of membrane voltage, rendered the interpretation of the results questionable. Thus, it was important to provide genetic evidence of the relevance of ion channels in vivo and ex vivo using a mammalian model of cardiac pacemaking.

The first hint from genetics for the field of pacemaking and $I_{\mathrm{f}}$ was published in 1997 and came from a large scale-based screening of mutations affecting the development of the zebrafish cardiovascular system (Stainier et al., 1996). Zebrafish is particularly amenable for studying the cardiovascular development because early embryos and larvae are transparent, and exchanges in oxygen are ensured by simple diffusion. Consequently, the developmental defects that will result in lethality in mammalian embryos can be studied in zebrafish larvae. Among 58 mutations identified in this study, the recessive slo mo mutation was characterized and shown to affect the heart rate of the embryo in the absence of other defects in cardiovascular development. The slo mo zebrafish mutant presented with slower basal heart rate compared to wild-type counterparts (Baker et al., 1997). Patch-clamp recordings of ionic currents from isolated embryonic cardiomyocytes showed a reduction in the density of the fast component of $I_{f}$ activation (referred to as $I_{h}$ in this study). No other ionic current known at the time to be involved in pacemaking in the rabbit sinoatrial node was found to be affected in the hearts of slo mo embryos, leading to the conclusion that diminished If was responsible for bradycardia in this strain. When homozygous slo mo mutants were raised to adulthood, they presented with bradycardia and reduced $I_{f}$ density in atria and ventricles (Warren et 
1 al., 2001). Unfortunately, this intriguing fish mutant was not investigated further to determine whether it was the funny channel itself, or a protein involved in channel regulation, that carried the slo mo mutation. Yet, the slo mo zebrafish mutant provided the first genetic evidence of funny current's relevance in determining the heart rate in vivo in vertebrates.

In 1998, Wickman and coworkers published the first paper in which an ion channel known to be involved in the regulation of sinoatrial pacemaker activity and heart was ablated by genetic knockout in mice (Wickman et al., 1998). These authors showed that genetic ablation of G proteinactivated $\mathrm{K}^{+}$channel 4 (Girk4) channels underlying $I_{K A C h}$ significantly reduced the degree of cholinergic regulation of heart rate under resting condition by $50 \%$ and inhibited the negative chronotropic response to pharmacological activation of muscarinic or adenosine receptors (Wickman et al., 1998). This study provided in-vivo evidence of the relevance of $I_{K A C h}$ in controlling heart rate. Since preparations of isolated mouse sinoatrial node pacemaker cells were not available in the nineties, Wickman and coworkers underscored in the Discussion section of their article that complete dissection of the role of other ion channels involved in cholinergic regulation of heart automaticity would have required the characterization of the mouse sinoatrial node. The last author of the present review article was largely convinced by this assertion and readily began working in this direction. Indeed, the identification of mouse SAN and the isolation of pacemaker cells were considered as hardly feasible, chiefly because of the tiny size of this region $\left(1 \mathrm{~mm}^{2}\right)$. However, in 2001, the journal Cardiovascular Research published a couple of articles on recordings of intracellular action potentials of the mouse SAN using sharp electrodes (Verheijck et al., 2001) and the first characterization of the funny current in pacemaker cells of mouse SAN (Mangoni and Nargeot, 2001). Since these first studies, the mouse SAN has become a popular model for studying the complex and partially elusive core of the pacemaker mechanisms.

The first study of ionic currents and $I_{f}$ in mouse SAN (Figure 1) confirmed that the current properties in mouse pacemaker tissue were similar to those previously described in the rabbit. Notably, none of the cloned HCN-channel kinetics known at the time matched perfectly those of mouse $I_{f}$, the current activation kinetics being slower than that recorded in cells expressing HCN1 or HCN2 alone, yet much faster than that of HCN4-mediated currents (Mangoni and Nargeot, 2001). These first data opened up the possibility of investigating the relevance of specific ionic currents, such as $I_{f}$, in the regulation of heart rate using genetically modified mice. Recordings of mouse SAN myocytes were then followed by a study on $I_{\mathrm{f}}$ in Purkinje myocytes (Miquerol et al., 2004) and on pacemaker myocytes from the mouse atrioventricular node (Mangoni et al., 2006; Marger et al., 
2. Contribution of different HCN isoforms to the funny current and consequences for genetically modified mice

Early experiments by Shi and co-workers in rabbit and rat heart showed that rodent cardiac tissues express transcripts of HCN1, HCN2, and HCN4 channels (Shi et al., 1999). In addition, they found that in rabbit SAN, expression of HCN4 is predominant (>81\%) relative to HCN1 (>18\%) and HCN2 (0.6\%) (Akbarali et al., 1999; Shi et al., 1999). In neonatal rat ventricles, known to express $I_{f}$, HCN2 mRNA was, instead, the dominant transcript with a 5:1 ratio of HCN2 to HCN4. A study by Ishi and co-workers (Ishii et al., 1999) confirmed that expression of the HCN4 isoform was prevalent in rabbit SAN and that the properties of the current resulting from heterologous expression of HCN4 were more similar to those of the native current as compared to the currents generated by HCN1 or HCN2 channels.

According to (Moosmang et al., 2001), also in the murine SAN, the most highly expressed HCN isoform is HCN4. However, in-situ hybridization experiments showed that, contrary to the findings of Shi and co-workers (Shi et al., 1999), HCN2 mRNA to be expressed more densely than HCN1 mRNA.

A first genome-scale regional ion channel expression profile in the mouse heart was obtained in 2005 (Marionneau et al., 2005). This study confirmed high expression of HCN1 and HCN4 in the SAN, and high expression in the atrioventricular node and atria. Significant HCN2 transcript levels were also detected in the SAN and ventricle. In the latter, HCN4 expression levels were found as well, while HCN3 expression was very low in all compartments. In conclusion, the expression profile found for the HCN gene family was consistent with previous studies in both rabbit and rat heart.

Whereas in early studies no significant expression of HCN3 mRNA was found in the cardiac conduction system or in the working myocardium, in later studies, the HCN3 isoform was shown to be expressed and functional in ventricular cells of murine heart (Fenske et al., 2011).

In conclusion, studies on the distribution of HCN transcripts in the heart provided important information that helped identify the potential composition of native funny channels, but they did not provide insights into the functional properties of native $I_{f}$, or its importance in mammalian pacemaking. Genetic targeting of $\mathrm{Hcn}$ gene family members and functional exploration of transgenic mice were the next steps aimed at advancing the knowledge of $I_{f}$ function. Since $I_{f}$ is encoded by different HCN isoforms showing different distributions and prevalence in the SAN, in the conduction system and in the working myocardium, it can be assumed that the generation of several mouse models based on the use of different gene targeting techniques will be required to address the role of 
1 funny current in the generation and regulation of heart automaticity. Additional complexity is to be expected when considering that native f-channels are heteromeric structures that are likely to be formed by more than one HCN isoform. Compensatory effects exerted by an isoform different from the deleted one are to be considered, too. Furthermore, f-channels may have different physiological roles and effects depending on the developmental stage of the organism, and on other organs in addition to the heart. Conditional and tissue-specific targeting is, thus, important. Finally, the generation of mouse models in which a function of $I_{f}$ is investigated without deletion of the channel protein is desirable. This last objective has been achieved by studying models carrying modified HCN4 devoid of cAMP-dependent regulation, or with silenced channel conductance (see below). In the next two sections, we will summarize insights obtained from the knockout of Hcn genes and from mice expressing modified HCN4 channels.

\section{Functional studies using genetic ablation of HCN channels}

A first approach exploiting genetically modified mice to investigate $\mathrm{HCN}$ function was developed by the generation of HCN2-deficient mice by systemic knockout of Hcn2 (Ludwig et al., 2003). As mentioned above, early measurements of mRNA had shown that, together with the predominant isoform HCN4, also HCN1 and HCN2 are expressed in the mouse SAN, but no evidence was available as to the relative importance of these two isoforms at the time. In the study by Ludwig et al., the functional role of HCN2 was investigated, and it was proposed that this isoform plays an important role in stabilizing mouse cardiac pacemaker activity (Ludwig et al., 2003). Indeed, telemetric recordings of ECG in mice globally deficient in HCN2 channels ( $\mathrm{Hcn2}^{-/}$) presented with sinus dysrhythmia, evidenced by highly increased inter-beat variability. Pacemaker myocytes isolated from $\mathrm{Hcn}^{-/-}$mice showed a 30\% reduction in $I_{f}$ density, associated with a negative shift of the maximum diastolic potential. Mice with a cardiac-specific Hcn2 knockout showed a similar phenotype, confirming that dysrhythmia was caused by intrinsic SAN dysfunction. Electrophysiological analysis of $I_{f}$ in cells isolated from the SAN revealed that the current kinetics, in both wild-type and mutant mice, were faster than HCN4-mediated currents recorded in heterologous expression experiments. The overall findings were consistent with the hypothesis that the funny current in mouse SAN pacemaker myocytes was generated by co-expression of HCN2 and HCN4 channels, and that HCN2 contributed to basal excitability of SAN myocytes. However, this conclusion was later challenged by data showing also a contribution of the HCN1 isoform to SAN $I_{f}$ (Fenske et al., 2013). The study by Ludwig et al. (Ludwig et al., 2003) did not only address the cardiac phenotype generated in $\mathrm{Hcn}^{-/-}$mice but also the electrophysiological and functional abnormalities caused by the Hcn2 deletion in the nervous system. The authors found that thalamocortical relay 
neurons displayed a pronounced hyperpolarization of the resting membrane potential.

2 Hyperpolarization was due to the deletion of the HCN2-mediated $I_{h}$ and induced a change in their firing patterns. This change in intrinsic excitability increased the susceptibility to oscillations and resulted in spontaneous absence seizures. The authors' study, thus, revealed an important role for HCN2 in both cardiac automaticity and the control of neuronal and thalamocortical network excitability.

Further insight into the contribution of HCN isoforms to pacemaker activity in mice was gained by studying the effects of Hcn4 knockout in the developing embryonic mouse heart (Stieber et al., 2003a). This study showed that mice globally deficient in HCN4 ( $\mathrm{Hcn}^{-/-}$), or mice with inducible cardiac-specific deletion of $\mathrm{Hcn} 4\left(\mathrm{cHcn}^{-/-}\right)$, exhibit embryonic lethality between $\mathrm{E} 9.5$ and E11.5. In embryonic hearts from HCN4-deficient mice, expression of $I_{f}$ was reduced by $85 \%$ relative to controls. Of note, while embryonic hearts still showed spontaneous contractions at a significantly slower rate, their beating rate could not be modulated by cAMP. Mutant cardiomyocytes displayed primitive low-amplitude spontaneous action potentials, but mature SAN-like action potentials, as recorded from day 9 post coitum (E9) in wild-type, could not be recorded. The authors concluded that HCN4 channels were essential for the basal activity of embryonic hearts even if, at least until E11.5, the heart rate was sustained, also in the absence of HCN4, by other mechanisms such as other cardiac HCN isoforms, or by spontaneous intracellular $\mathrm{Ca}^{2+}$ cycling (Viatchenko-Karpinski et al., 1999).

The relevance of the HCN1 isoform to mouse pacemaker activity was evaluated by analyzing mice globally deficient in HCN1 (Hcn1 ${ }^{--}$) (Fenske et al., 2013). In this study, HCN1 protein expression was analyzed in the SAN. HCN1 was found to be highly expressed and co-localized with HCN4. In-vivo exploration of heart rate and rhythm in $\mathrm{Hcn1}^{-/-}$mice showed these channels play an important role in determining SAN function. Hcn1 $1^{-/-}$mice displayed hallmarks of SAN dysfunction including bradycardia, sinus dysrhythmia, prolonged SAN recovery, and prolonged conduction time, as well as recurrent sinus pauses. Electrophysiological characterization of $\mathrm{Hcn} 1^{-/-}$SAN myocytes showed a significant reduction in $I_{f}$ current density and slowing of current activation kinetics in line with the hypothesis of HCN1 contributing to the fast component of $I_{f}$ activation, in comparison to the kinetics of HCN4 currents recorded in heterologous expression systems. Spontaneous action potentials in SAN pacemaker myocytes of $\mathrm{Hcn}^{-/-}$mice had slower frequency and displayed an arrhythmic-like phenotype with pronounced beat-to-beat interval variations. Overall, this work has provided insight into the role of HCN1 in the SAN and thus laid the foundation for a mechanistic understanding of potential HCN1-based SAN dysfunction in humans.

Until 2011, Hcn4 knockout mice were generated using non-conditional deletion strategies, either global or cardiac-specific (Stieber et al., 2003a), or Cre-loxP techniques allowing systemic 
1 inducible knockout in adulthood (Herrmann et al., 2007). While, as we have mentioned above, constitutive global or cardiac-specific $\mathrm{Hcn}^{-/-}$mice died in utero, inducible knockout mice exhibited mild effects on cardiac automaticity and heart rate control, although some hallmarks of SAN dysfunction were recorded in these mice. These include SAN pauses, or an increase in the beat-tobeat variability of heart rate, which is indicative of a reduction in the SAN-diastolic depolarization reserve after the loss of $I_{f}$ function (Herrmann et al., 2007). The distinction between effects of global cardiac-specific deletion of Hcn4 and selective knockout in the rhythmogenic centers is of interest, which was attempted by generating a mouse model of selective Hcn4 knockout in the SAN. In this mouse model, the tamoxifen-inducible Cre recombinase (CreERT2) was knocked into the Hcn4 gene itself (Hcn4 ${ }^{C r e E R T 2}$ ) (Hoesl et al., 2008). Analysis of this line showed reporter gene deletion in the SAN and AVN, but not in Purkinje fibers, allowing a mouse model to be generated in which deletion of Hcn4 was selectively achieved in the SAN and AVN (Hcn4-KiT mouse) (Hoesl et al., 2008). Similarly to observations with respect to the cardiac-specific Hcn4 knockout, tamoxifen-inducible deletion in the SAN during adulthood resulted in SAN pauses without significant slowing of basal heart rate. Furthermore, neither global cardiac nor SAN-AVN-specific deletion of Hcn4 altered the heart chronotropic competence, indicating that mechanisms other than $I_{f}$ were also involved in the autonomic control of the heart (Hoesl et al., 2008). The same authors employed an identical $H c n 4^{\text {CreERT2 }}$ line to obtain recombination-dependent expression of diphtheria toxin in SAN cells. This is expected to induce the selective death of HCN4-expressing cells within the SAN. Tamoxifeninducible selective deletion of HCN4-expressing cells in the SAN, intriguingly, resulted in a mild phenotype, which, again, was characterized by SAN pauses and by only a moderate increase in models, these authors proposed that, in adulthood, If primarily constitutes a depolarization reserve that ensures pacemaking under negative chronotropic challenges and is not required for generating automaticity per se.

In 2011, Baruscotti and co-workers generated another tamoxifen-inducible and cardiacspecific Hcn4 knockout mouse model based on the Cre-loxP system (Baruscotti et al., 2011). Telemetric recordings of ECG showed that daily injections of tamoxifen in adult mice carrying the $H c n 4^{l o x / l o x, C r e}$ gene to induce Hcn4 deletion led to progressive slowing of heart rate. Heart rate slowing was accompanied by second-degree atrioventricular blocks, subsequently degenerating into complete heart block. Lethality because of heart block occurred when heart rate was approximately 50\% of basal rate before tamoxifen injection, and ECG showed only isolated P waves and no QRS complex could be recorded (Baruscotti et al., 2011). None of the 14 mutant mice receiving tamoxifen treatment survived more than 8.5 days. By contrast, no effect was observed in control mice receiving the same 
treatment. As expected, the time course of spontaneous action potential firing rate in SAN myocytes isolated from either control or mutant mice during tamoxifen treatment paralleled that of the heart rate of free-moving animals. All mutant mice developed complete atrioventricular block leading to heart arrest upon treatment with tamoxifen. These data led to the assumption that HCN4 channels are required for normal rhythm generation and conduction and represent a key molecular mechanism for cardiac pacemaking (Baruscotti et al., 2011). The reasons for these differences in phenotype severity between different inducible cardiac-specific Hcn4 knockouts are not yet understood.

Of note, all these mice display hallmarks of SAN dysfunction, such as SAN pauses or increased susceptibility to cholinergic challenge. Notably, the phenotype of HCN4 knockout mice reported by Baruscotti and co-workers is qualitatively close to that observed in mice expressing silenced $I_{f}$ current (Mesirca et al., 2014) (see below).

\section{Genetic silencing of cAMP-dependent regulation of f-channels}

The control of the funny current by direct binding of intracellular cAMP to f-channels and the associated cAMP-dependent modulation of heart rate represent landmark findings of the early investigation of processes involved in the autonomic control of cardiac function (DiFrancesco and Mangoni, 1994; DiFrancesco and Tortora, 1991). Like most findings collected on funny current properties and pacemaker activity in the eighties and nineties, these data were obtained in the rabbit SAN. After the cloning of HCN channels, it became apparent that cAMP-dependent activation can substantially vary among different HCN isoforms. According to data from early heterologous HCN expression experiments, HCN2 and HCN4 isoforms were more sensitive to cAMP than was the HCN1 isoform, with cAMP-induced shifts in the order of 15-16 mV for HCN2 and HCN4, relative to shifts in the order of 2-7 mV for HCN1 (Moroni et al., 2001). Since native $I_{f}$ current shifts were intermediate between these values (about 10-11 mV (DiFrancesco et al., 1986)), these observations gave rise to the hypothesis that native funny channels could result from dimeric expression of different isoforms (Altomare et al., 2003; Moroni et al., 2001; Stieber et al., 2003b). Genetic manipulation of cAMP-dependent regulation of HCN channels combined with time- and tissuespecific control of HCN expression in mice provided new important insights into the contribution of $I_{f}$ to the regulation of heart rate.

In 2008, (Harzheim et al., 2008) reported on mice with HCN4 channels deficient in cAMPdependent binding and regulation. By introducing the knock-in mutation R669Q in the CNBD, binding of cAMP to HCN4 channels was abolished. This mutation was lethal during embryonic development at day E11 in homozygous, but not in heterozygous mutants. Analysis of adult 
heterozygous mutant mice showed an increased number of sinus pauses and sinoatrial blocks after exercise, but the authors did not find significant changes in resting heart rate. Recordings of $\mathrm{I}_{\mathrm{f}}$ in isolated SAN myocytes showed that the wild-type current had faster activation and slower deactivation kinetics than the current recorded from heterozygous mutant mice. These results led the authors to suggest that the major function of cAMP-dependent regulation of HCN4 in adult mice is to prevent sinus pauses, and that this function can only be fulfilled when channels are activated by cAMP. In addition, these data indicated that cAMP-dependent regulation of HCN4 is necessary for terminal development of the mouse embryo.

A different approach to assess the role of cAMP-dependent regulation of SAN f-channels was developed by Alig and co-workers in 2009 (Alig et al., 2009). They generated mice with heartspecific and time-controlled expression of dominant negative human HCN4 channel (hHCN4-573X) with truncated C-terminus and cAMP-binding domain deficiency (Figure 2). These mutant HCN4 channels recapitulate the human HCN4-573X mutation that is predicted to abolish the cAMPdependent control of HCN channels present in a founder individual with primary SAND (SchulzeBahr et al., 2003). One potential advantage of this approach is the possibility of selectively affecting one of more functional properties of $\mathrm{f}$-channels without deleting the protein itself, possibly sparing functions that depend on channel scaffolding or compartmentalization. In addition, it is possible to keep the expression of the mutant channel at low levels compared to endogenous channels while still obtaining total silencing of, for example, cAMP regulation. Indeed, the probability that a significant number of HCN tetramers contain no mutant dominant-negative HCN subunits is very low (Alig et al., 2009). Immunoblotting experiments showed expression of hHCN4-573X protein predominantly in the SAN and atria (Alig et al., 2009). If in SAN myocytes expressing mutant hHCN4-573X channels showed normal current densities but displayed a hyperpolarized half-activation and total insensitivity to the adrenergic agonist isoproterenol. Expression of hHCN4-573X induced quiescence in a significant number of SAN myocytes and decreased the maximal spontaneous rate of pacemaker activity. The in-vivo heart rate of conscious hHCN4-573X mice has been measured at different degree of spontaneous physical activity. The heart rate of hHCN4-573X mice was consistently slower than that of control mice at both low and high degrees of physical activity by $\approx 80$ beats per minute (see Fig. 5 in Alig et al., 2009) (Alig et al., 2009). On the one hand, these data demonstrated that cAMPmediated control of $I_{f}$ is important in the regulation of basal and maximal frequency of SAN cells and of heart rate, providing evidence that $I_{f}$ plays a significant role in setting pacemaker rhythm at rest and during activity. On the other hand, heart rate adaptation to physical activity remained functional in transgenic mice expressing hHCN4-573X, thus indicating that mechanisms other than $I_{f}$ can regulate heart rate under adrenergic activation. This finding is not entirely surprising because 
abolishment of the $I_{f}$ contribution to cAMP-dependent modulation of heart rate does not eliminate the contribution of other ion channels sensitive to cAMP-dependent regulation such as L-type Cav1.3 channels and ryanodine receptor-dependent intracellular $\mathrm{Ca}^{2+}$ release (Baudot et al., 2020; Mangoni et al., 2003; Torrente et al., 2016; Vinogradova et al., 2002) .

\section{Interaction between depolarizing and hyperpolarizing contributions to pacemaker activity and relation to autonomic control of rate in mouse SAN: role of the funny current.}

All the results discussed above clearly indicate that cardiac rhythmogenesis is a complex mechanism involving several actors that possibly play redundant or complementary roles. This suggests that an accurate description of the pacemaker mechanism could be achieved by combining the genetic manipulation of multiple ion channels in the same animal.

In 2013, Mesirca and co-workers (Mesirca et al., 2013) investigated the effects of genetic ablation of $\mathrm{G}$ protein-gated $\mathrm{K}^{+}$channel 4 channels (Girk4), which encode the muscarinic-activated $\mathrm{K}^{+}$current $\left(I_{K A C h}\right)$. The cardiac $\mathrm{K}_{\mathrm{ACh}}$ channel is a heterotetramer composed of GIRK1 and GIRK4channel subunits (Wickman et al., 1997). However, because GIRK4 subunits are required for cellular trafficking of GIRK1, knockout of Girk4 results in the complete loss of cardiac $I_{K A C h}$ (Wickman et al., 1998). Girk4 knockout Girk4 $4^{-/}$mice exhibit slightly increased basal heart rate (10\%) and a reduction of about $50 \%$ in the high- and low-frequency domain spectra of heart rate variability (Mesirca et al., 2013; Wickman et al., 1998). The negative chronotropic effect of acetylcholine (ACh) on pacemaker activity of isolated SAN myocytes was similarly reduced by $50 \%$. Genetic ablation of $I_{K A C h}$ did not affect other major ionic currents $I_{f}$ and $I_{C a L}$ (Mesirca et al., 2013). In vivo, Girk4 ${ }^{-/-}$mice displayed prolonged recovery time of basal heart rate after physical exercise, or after $\beta$-adrenergic stimulation of heart rate via intraperitoneal injection of isoproterenol. This work revealed that $I_{K A C h}$ is an important mechanism in mouse SAN physiology for mediating recovery of resting heart rate after adrenergic activation. This function was previously undetected in the SAN of other species such as the rabbit (DiFrancesco et al., 1989) and illustrates the importance of genetically-modified mice in the field of cardiac automaticity. In addition, these data strongly suggested that $I_{K A C h}$ acts as a permanent background brake of heart rate, in addition to the previously known regulatory effect on heart rate variability. This view has been confirmed in mice expressing silenced f-channels (see below).

\section{(1)}


The contribution of $I_{K A C h}$ to autonomic-driven control of rhythm raises the question of whether this knowledge can be used to gain an understanding of the role of $I_{f}$ under physiological or pathological conditions. In general, the diastolic depolarization phase in SAN pacemaker myocytes can be visualized as a sort of racing car equipped with both an accelerator and a brake mechanism that can be controlled by autonomic nervous system stimulation of $\beta$-adrenergic and muscarinic receptors, respectively, resulting in a fine tuning of heart rate. In such a complex machinery, $I_{f}$ acts, among other channels, as an accelerator, while $I_{K A C h}$ has the role of a brake (see metaphoric cartoon in Figure 1 of DiFrancesco (DiFrancesco, 2006)). To put these considerations in a concrete experimental context, and to take into account the correct reciprocal equilibrium between accelerating and decelerating elements needed for a proper control of normal physiological functions, Mesirca and co-workers (Mesirca et al., 2014) proposed that SAN dysfunction and atrioventricular block secondary to removal of a diastolic depolarization accelerator mechanism, such as the contribution of $I_{f}$, could be rescued by inactivating the $I_{K A C h}$-mediated brake. To test this hypothesis, a complete conditional and time-controlled silencing of the funny current was achieved by expression of another dominant-negative, non-conductive hHCN4-channel subunit (hHCN4-AYA). The advantage of this approach is "silencing” $I_{f}$ conductance without removal of HCN channel proteins. This point can be important, since the effects of HCN deletion on scaffolding and organization of membrane caveolar microdomains in SAN myocytes (Barbuti et al., 2007) are unknown. This strategy is similar to that applied for creating mice expressing dominant-negative hHCN4-573X channels (Alig et al., 2009). Two lines of transgenic mice carrying the tTA transactivator and the mutant HCN4 are crossed (Figure 3). The resulting double transgenic mice are deprived of doxycycline, and the expression of dominant negative hHCN4-AYA channels is triggered to reach a maximum three weeks after antibiotic removal (Figure 3). This mouse model was characterized by electrophysiological analysis of single pacemaker cells and in-vivo telemetric ECG recordings. Complete silencing of $I_{f}$ in automatic myocytes of the SAN, the atrioventricular node and Purkinje fibers network had profound consequences on automaticity. Expression of mutant channels led to a dramatic drop in the action potential basal firing rate and in the occurrence of delayed afterdepolarizations (DADs) of membrane voltage, as well as in a failure of action potential generation in all three cell types analyzed. Intracellular $\mathrm{Ca}^{2+}$ dynamics was also disrupted upon $I_{f}$ silencing, resulting in the loss of the coordination of local $\mathrm{Ca}^{2+}$ release events, which normally lead to the generation of diastolic inward $\mathrm{Na}^{+} / \mathrm{Ca}^{2+}$ exchanger current and cell-wide calcium transients in wild-type SAN myocytes (Vinogradova et al., 2002). Confocal microscope line-scan analysis did not only confirm the generation of DAD events in mutant SAN pacemaker cells but also the decrease in the frequency of 
1 spontaneous intracellular $\mathrm{Ca}^{2+}$ transients, which was only partially rescued under perfusion of increasing doses of isoproterenol. Following withdrawal of doxycycline from the diet and the resulting onset of hHCN4-AYA protein expression, the mutant mouse experienced progressive slowing of heart rate, accompanied by atrioventricular blocks, ventricular extrasystoles, and ventricular tachycardia (Mesirca et al., 2014). Once the interaction between the components working in opposite directions with respect to the control of cardiac rhythmogenesis was confirmed, the HCN loss-of-function in mutant mice was counterbalanced by crossing them with the Girk $4^{-/-}$mouse strain (Mesirca et al., 2013). Indeed, ECG recordings of double-mutant hHCN4-AYA/Girk4-- mice revealed improved heart rate in comparison to hHCN4-AYA counterparts and prevention of SAN pauses, atrioventricular dysfunctions and ventricular arrhythmia. These novel findings highlighted the importance of studying cardiac rhythmogenesis as a concerted balance between diverse ion channels with complementary physiological roles. The study by Mesirca and co-workers was the first to provide direct evidence of an interplay between an inward current $I_{f}$ and an outward current $I_{K A C h}$ in generating heart automaticity, as originally proposed by Noble and co-workers for $I_{f}$ and background currents using a numerical model of SAN automaticity (Noble et al., 1992). The work by Mesirca et al. led also to the concept of "compensatory" targeting of $I_{K A C h}$ to rescue sinus node dysfunction (Mesirca et al., 2016a; Mesirca et al., 2016b). Indeed, beside hHCN4-AYA mice, we have recently showed that genetic ablation or pharmacologic inhibition of $I_{K A C h}$ can rescue sinus node dysfunction and atrioventricular block in mice lacking L-type $\mathrm{Ca}_{\mathrm{v}} 1.3$ and T-type Cav3.1 channels (Bidaud et al., 2020a; Mesirca et al., 2016a). Finally, have showed also that the $I_{K A C h}$ blocker tertiapin-Q normalizes the heart rate of mice expressing hHCN4-573X (Bidaud et al., 2020a). In conclusion, beside $I_{f}$, the concept of $I_{K A C h}$ targeting to restore the balance between inward and outward currents in pacemaking has been now extended to include other accelerators of diastolic depolarization such as L-type and T-type $\mathrm{Ca}^{2+}$ channels (Bidaud et al., 2020a; Mesirca et al., 2016a). It will be interesting to know if this interplay between inward and outward currents, which determines the cell's depolarization reserve, also applies to the cardiac $\mathrm{Na}^{+} / \mathrm{Ca}^{2+}$ exchanger current (NCX1), which is another important contributor to the SAN depolarization reserve and an accelerator of diastolic depolarization (Bogdanov et al., 2001; Gao et al., 2013; Torrente et al., 2015) in cooperation with $I_{f}$ (Kohajda et al., 2019). In this respect, Mesirca and co-workers showed that automaticity in SAN myocytes isolated from Girk4 ${ }^{--}$mice has reduced sensitivity to application of ryanodine in comparison to automaticity of wild-type counterparts (Mesirca et al., 2016a).

In the same vein as Mesirca's et al.'s work, a study by Fenske and co-workers (Fenske et al., 2020) provided further insight into the role of HCN4 in cAMP-dependent regulation of pacemaker activity and rate control by the autonomic nervous system using a knock-in mouse model expressing 
cAMP-insensitive HCN4 channels (HCN4FEA) (Fenske et al., 2020). While hHCN4-AYA

2 expressing mice enable studying the role of $I_{f}$ without disrupting channel protein, the main advantage of the HCN4FEA mouse model resides in the possibility of studying the physiological role of cAMPdependent regulation of $I_{f}$ without causing direct channel loss-of-function. Similarly to $I_{f}$ in mice expressing hHCN4-573X-channel subunits, HCN4FEA channels are insensitive to cAMP, yet their half-activation voltage is more positive compared to that of wild-type controls. hHCN4-573X and HCN4FEA mice are thus highly complementary, because activation of $I_{f}$ in hHCN4-573X-expressing myocytes is set as if intracellular concentration of cAMP was very low, while HCN4FEA channels mimic a slightly increased basal cAMP concentration. Fenske and co-workers proceeded on the assumption that one of the main functions of HCN4 channels is to counteract slowing of heart rate induced by vagal stimulation, that is, to prevent parasympathetic override, detrimental rate slowing, and deep bradycardia (see review article by Hennis et al. 2021, in this issue)(Hennis et al., 2021). As in previous studies in which the reduction or removal of HCN4 contribution to activity was investigated, the HCN4FEA mice exhibited bradycardia within a complex phenotype that was also characterized by sinus pauses, showing the importance of $I_{f}$ in dynamic regulation of heart rate. The authors proposed that rate slowing caused by removal of cAMP modulation of HCN4 is due to the presence of non-firing cells, which interact with firing cells in a tonic entrainment process. cAMP activation of HCN4 channels increases the fraction of firing vs non-firing cells, thus representing a mechanism that opposes augmented responses to vagal stimulation (Fenske et al., 2020).

\section{Notes on the role of the funny current in the atrioventricular node}

The atrioventricular node ensures conduction of the SAN impulse between the atria and ventricles. In addition, the atrioventricular node is able to drive the heartbeat in case of SAN failure. Even if the role of $I_{f}$ is generally thought to be prominent in pacemaking, genetically modified mice have provided evidence of an important role of the funny current in impulse conduction in the atrioventricular node. In 2011, Baruscotti and co-workers reported that atrioventricular node myocytes isolated from tamoxifen-treated Hcn $4^{\text {lox/lox,Cre }}$ mice showed about $50 \%$ reduction in $I_{f}$ density associated with the occurrence of atrioventricular conduction block (Baruscotti et al., 2011). In the same year, Marger et al. showed that, while hHCN4-573X-expressing mice did not show atrioventricular dysfunction, atrioventricular myocytes isolated from these mutants displayed $\approx 65 \%$ slowing of pacemaker activity in comparison to control myocytes (Marger et al., 2011a). The work by Mesirca et al. in 2014, was the first to correlate severe atrioventricular dysfunction with silencing of $I_{f}$ and reduced pacemaker activity in atrioventricular myocytes expressing hHCN4-AYA channels 
1 (Mesirca et al., 2014). Importantly, it showed also that atrioventricular block in mice expressing hHCN4-AYA subunits was highly correlated with onset of sustained ventricular tachycardia (Mesirca et al., 2014). In further support of a role of $I_{f}$ in atrioventricular conduction, mouse models in which TRPM7 channels have been genetically ablated, show diminished $I_{f}$ densities in the atrioventricular node and display atrioventricular blocks (Sah et al., 2013a; Sah et al., 2013b). Clinical studies indicate that athletes are more prone to atrioventricular block than the general population. This phenomenon provided an exciting chance to test the role of $I_{f}$ in atrioventricular conduction in a very relevant way using mouse models of long-term training and in vivo ECG recordings in racing horses (Mesirca et al., 2021b). Mesirca and co-workers have reported that mice trained for 5 months to swimming develop $1^{\text {st }}$ degree atrioventricular block, similarly to racing horses. Consistent with observations in training induced SAN bradycardia, atrioventricular block was due to downregulation of HCN4 mRNA and $I_{f}$.

It may seem counterintuitive that a slow-onset current activated upon hyperpolarization can play an important role in impulse conduction, which is generally considered to be reliant on faster voltage gated currents activated upon depolarization. However, this apparent paradox can be solved by considering the concept of depolarization reserve, as it applies for the SAN diastolic phase. First, spontaneously active mouse atrioventricular node myocytes express lower $I_{f}$ densities in comparison to SAN myocytes (Marger et al., 2011b). More generally, previous work in mouse atrioventricular node myocytes has demonstrated lower densities of the principal ionic currents involved in pacemaking including $\mathrm{Ca}_{\mathrm{v}} 1.3$-mediated $I_{C a L}$ and $\mathrm{Ca}_{\mathrm{v}} 3.1$-mediated $I_{C a T}$ as compared to SAN myocytes (Marger et al., 2011a; Marger et al., 2011b). This suggests the total depolarization reserve of the atrioventricular node to be lower than that of the SAN. On one hand, this will render the SAN automaticity dominant over that of the atrioventricular node. On the other hand, $I_{K A C h}$ activated by vagal input will more easily destabilize conduction in the atrioventricular node after genetic silencing of $I_{f}$ or genetic ablation of HCN4. In support of this hypothesis, is the observation that knockout of $I_{K A C h}$ restored atrioventricular conduction and prevented ventricular tachycardia in mice expressing hHCN4-AYA channels (Mesirca et al., 2014). Similarly to $I_{f}$ silencing, genetic ablation of $I_{K A C h}$ restored atrioventricular conduction in $\mathrm{Ca}_{v} 1.3^{-/-}$mice (Mesirca et al., 2016a).

Taken together, these studies have demonstrated a previously unexpected role of the funny current in atrioventricular conduction, but also in stabilizing ventricular rhythm. Future studies will 
Since the first mouse model of knockout of $I_{K A C b}$ in 1998 (Wickman et al., 1998) and description of mouse SAN automaticity in 2001 (Mangoni and Nargeot, 2001; Verheijck et al., 2001), many genetically modified mice have been created to study the role of $I_{f}$ and other currents involved in pacemaker activity. For more exhaustive overview of mouse models of ion channels involved in heart automaticity, as well as of models of inherited sinus node dysfunction and arrhythmias, the reader is referred to recent review articles (Mesirca et al., 2021a; Wallace et al., 2021).

As a general outcome, genetically modified mice carrying a Hcn gene knockout and mice expressing modified HCN isoforms have confirmed that $I_{f}$ plays an important role in the generation of SAN function, atrioventricular conduction and basal heart rate. Indeed, while the degree of severity of the phenotype varies among models and gene targeting approaches, SAN dysfunction is a consistent finding (see sections 3-5). Reasons for the variability in phenotype severity between different knockouts of Hcn4 are poorly understood. Some potential factors may be considered. First, the exact composition in HCN subunits of SAN f- channels has not been fully elucidated, even if we assume HCN4 to be the predominant channel subunit. The possibility that residual HCN1 and HCN2 subunits may compensate for the loss of HCN4 in models, at different developmental stages and adulthood would need further investigation. In addition, different promoter lines driving expression of Cre recombinase in the heart and the SAN may have variable efficiency, leaving significant amounts of residual HCN4 in cell groups within the SAN or the conduction system. Finally, another important point is the capability of the physiological system to compensate for $I_{f}$ loss-of-function in the heart. Intact HCN4 function is a critical factor for heart automaticity in the embryo, while other currents may compensate for Hcn4 knockout or pharmacologic inhibition of $I_{f}$ in adulthood, when the conduction system is fully developed, and the set of ion channels involved in pacemaking is fully expressed.

The mouse SAN has been used also for deciphering the role of $I_{f}$ in important physiological processes in the heart that are independent from the autonomic nervous system. The role of $I_{f}$ in setting the basal heart rate has been explored also in a mouse model of SAN bradycardia induced by training (D'Souza et al., 2014). It has been shown that physical training induces slowing of basal heart rate by a mechanism that is independent from the input of parasympathetic nervous system but is due to downregulation of mRNA coding for HCN4 and $I_{f}$ density, leading to a decrease of the intrinsic SAN beating rate (D'Souza et al., 2014). A recent work by D’Souza and co-workers shows that daynight regulation of HCN4 expression underlies circadian variations of SAN pacemaking and heart rate, again independently from the input of the parasympathetic nervous system (D'Souza et al., 2021). Regulation of the day-night cycle of intrinsic SAN automaticity is possibly one of the most 
1 important roles of the funny current in cardiac physiology. While these mouse models of $I_{f}$ function 2 do not involve direct genetic manipulation, they are supportive of the role of this current in 3 determining the heart rate as observed in different genetic models of HCN4 function in the heart (see also article by Boyett et al. in this issue).

It is a general observation that the heart rate and pacemaker myocytes of adult mice carrying loss-of-function of $I_{f}$ or cAMP-dependent regulation of HCN4 do not show reduced response to sympathetic agonists, irrespectively of the severity of the phenotype, thereby demonstrating that other currents are involved in sympathetic regulation of cardiac automaticity. The NCX1 current is a core component of the coupled clock model of pacemaking (Lyashkov et al., 2018). NCX1 activity has been proposed to couple with spontaneous local $\mathrm{Ca}^{2+}$ release from ryanodine receptors of the sarcoplasmic reticulum to initiate diastolic depolarization and mediate its regulation by the sympathetic nervous system (Lakatta et al., 2010). In line with this model, mice carrying knockdown of expression of NCX1 shows normal basal heart rate but a significant reduction of positive chronotropic response to isoproterenol (Gao et al., 2013). This is consistent with other works reporting reduction of sympathetic regulation of heart rate in mouse models of loss-of-function of type 2 ryanodine receptors (Bround et al., 2012; Shan et al., 2010). If the cardiac phenotype of mouse models carrying phosphorylation defective type 2 ryanodine receptors align with the coupled clock model of pacemaking, paradoxical results on SAN automaticity have been obtained in mouse models of inherited catecholaminergic polymorphic ventricular tachycardia (CPVT) (Neco et al., 2012; Wang et al., 2017). These mice show SAN bradycardia, despite increased basal and isoproterenol stimulated $\mathrm{Ca}^{2+}$ release from type 2 ryanodine receptors. SAN bradycardia has been explained by reduced sarcoplasmic reticulum $\mathrm{Ca}^{2+}$ load and concomitant tonic $\mathrm{Ca}^{2+}$ dependent inhibition of $I_{\mathrm{CaL}}$ (Neco et al., 2012; Wang et al., 2017).

While we can consider that the activity of NCX1 supports automaticity following loss-offunction of $I_{f}$, recent data show that the funny current contributes to automaticity in mice with an atrial knockout of NCX1 (Torrente et al., 2015). Indeed, SAN automaticity in these mice is characterized by burst activity, in which automaticity alternates with periods of quiescence. Torrente and co-workers have shown that automaticity in isolated SAN/Atria preparations is slowed by the $I_{f}$ blocker ivabradine (Torrente et al., 2015). This work also revealed that arrest of pacemaker activity in NCX1 deficient SAN can be rescued by inhibition of $\mathrm{Ca}^{2+}$ activated $\mathrm{K}^{+}$channels, again showing that several classes of ionic channels contribute to set the pacemaker action potential (Yue et al., 2020).

Accumulating evidence shows that L-type $\mathrm{Ca}_{\mathrm{v}} 1.3$ channels are a major component of the cardiac pacemaker mechanism. Indeed, $\mathrm{Ca}_{v} 1.3$ channel contribute to pacemaking in the mouse SAN 
1 by at least three pathways. First, they drive $\mathrm{Ca}^{2+}$ current throughout the range of voltage spanning the diastolic depolarization (Mangoni et al., 2003; Torrente et al., 2016). Second, this $\mathrm{Ca}^{2+}$ current controls diastolic ryanodine receptor dependent $\mathrm{Ca}^{2+}$ release during pacemaking (Torrente et al., 2016). Third, $\mathrm{Ca}_{\mathrm{v}} 1.3$ channels constitute a necessary molecular component of the sustained inward $\mathrm{Na}^{+}$current $I_{s t}$ (Toyoda et al., 2017). Consistent with these multiple pathways of contribution to pacemaking automaticity of $\mathrm{Ca}_{v} 1.3^{-/-}$SAN/atria preparations and that of isolated SAN myocytes is reduced by $\approx 80 \%$ after inhibition of $I_{f}$ by ivabradine (Baudot et al., 2020). These data strongly suggest that $\mathrm{Ca}_{\mathrm{v}} 1.3$ channels constitute an effective mechanism sustaining automaticity under conditions of loss-of-function of the funny current.

\section{Conclusions and future directions}

Genetic targeting of the funny current in mice has provided new insights in the functional role of HCN channels in heart automaticity in general, but also into the role that other ion channels play in the cardiac pacemaker mechanism in vivo. This novel knowledge has confirmed early basic concepts on the relevance of the funny current and introduced new evidence of previously unknown mechanisms that demonstrate the high degree of complexity of the pacemaker process. At the same time, genetic studies on mice models have opened new research avenues for studying the mechanisms controlling pacemaker activity in arrhythmic disease. Genetically modified mice have demonstrated translational relevance also for studying the mechanistic bases of inherited or acquired SAN dysfunction and atrioventricular block in humans. For example, mice expressing hHCN4-573X channels (Alig et al., 2009) have helped elucidate the mechanism of familial $I_{f}$-mediated SAN bradycardia (Schweizer et al., 2010). Mice expressing hHCN4-AYA channels (Mesirca et al., 2014) present phenotypic traits similar to familial SAN dysfunction associated with ventricular tachycardia due to mutation in the HCN4 channel pore (Milano et al., 2014; Schweizer et al., 2014). hHCN4AYA as models of HCN4-related rhythm disease, and $C a_{v} 1.3^{-/}$and $C a_{v} 1.3^{-\%} C a_{v} 3.1^{\%}$ mice, as models of inherited SAN dysfunction (Baig et al., 2011) and congenital heart block (Torrente et al., 2020), respectively, have also demonstrated the relevance of $I_{K A C b}$ in establishing SAN dysfunction and atrioventricular block, opening a new avenue of research on GIRK channels as therapeutic targets for managing SAN disease (Mesirca et al., 2016a; Mesirca et al., 2016b). Finally, mouse models of SAN bradycardia and atrioventricular block in athletes (Bidaud et al., 2020b; D'Souza et al., 2014; Mesirca et al., 2021b) are providing and invaluable contribution for understanding the role of $I_{f}$ in acquired 
1 bradycardia and will constitute precious models to test innovative therapeutic strategies (See the 2 article by Boyett et al. in this issue).

In the future, new insights into the role of the funny current in pacemaking may be obtained 4 using mice with complex genotype involving targeting of more than one ion channel (see for example work by Baudot and co-workers in 2020) (Baudot et al., 2020). Such an approach could be combined

6 with pharmacology and biophysics of ion channels, to overcome some limitations of gene knockout 7 approaches. It will be also important to further extend the use of mouse models for studying the 8 mechanisms of congenital disease of SAN pacemaking. This could be achieved by creating mutant 9 mice in which mutations causative of SAN dysfunction and heart block are inserted in the mouse 10 genome. This approach could be facilitated by the current availability of patients' databases of 11 rhythmic disease and Crisper-Cas9 directed mutagenesis. In addition, specific targeting of cellular 12 subpopulations within the SAN could be achieved using data obtained from single-cell RNA 13 sequencing of the SAN, the atrioventricular node and Purkinje fibres, which may help identify new 14 markers of unique pacemaker myocytes. This approach of "intersectional genetics" of specific classes 15 of pacemaker myocytes, combined with Cre -mediated recombination of construct alleles may uncover new roles of the funny current, as well as other ion channels and receptors in heart automaticity. Targeting HCN channels in specific subsets of pacemaker myocytes may also provide new insights into the role of the funny current in cellular networks within the SAN, as recently proposed by two recent works on the role of local diastolic $\mathrm{Ca}^{2+}$ release (Bychkov et al., 2020) and the CNBD domain of HCN4 (Fenske et al., 2020). 


\section{Acknowledgments}

4 Matteo E. Mangoni wishes to acknowledge the paramount importance of the years he spent in Dario DiFrancesco's laboratory working on the funny current during his PhD in Physiology (1989-1994).

6 He also wishes to thank Joël Nargeot for his mentorship in studying the biology of voltage-gated 7 calcium channels between 1995 and 1999, and for having supported the first recordings of the funny 8 current in sinoatrial node pacemaker myocytes in 2000-2001. He thanks also Wayne R. Giles for the 9 time spent at the University of Calgary (2001-2004) and for important scientific collaboration. Special 10 thanks go to Jacqueline Alig for characterizing the hHCN4-573X expressing mouse lines. We also 11 thank Laurine Marger for recording the funny current in hHCN4-573X expressing mice, and for the 12 work she provided in studying pacemaker myocytes of the mouse atrioventricular node and Purkinje 13 fibers. We thank the Réseau d'Animaleries de Montpellier (RAM) of the Biocampus facility for the 14 mouse lines. We wish to thank all personnel of the PCEA mouse breeding facility in Montpellier, and 15 of the iExplore platform, for their help in the functional exploration of our collection of genetically 16 modified mice.

\section{Funding}

19 The IGF research group is a member of the Laboratory of Excellence "Ion Channel Science and 20 Therapeutics”, supported by a grant from ANR (ANR-11-LABX-0015). This work has been 21 supported by the Fondation pour la Recherche Medicale "Physiopathologie Cardiovasculaire" 22 (DPC20171138970 to M.E.M.), by the Agence Nationale de Recherche (ANR-15-CE14-0004-01 to M.E.M.), and by the Fondation Leducq (TNE FANTASY 19CVD03 to M.E.M.). 
References

Akbarali, H.I., Thatte, H., He, X.D., Giles, W.R. and Goyal, R.K., 1999. Role of HERG-like K(+) currents in opossum esophageal circular smooth muscle, Am J Physiol. 277, C1284-90.

Alig, J., Marger, L., Mesirca, P., Ehmke, H., Mangoni, M.E. and Isbrandt, D., 2009. Control of heart rate by cAMP sensitivity of HCN channels, Proc Natl Acad Sci U S A. 106, 12189-94.

Altomare, C., Terragni, B., Brioschi, C., Milanesi, R., Pagliuca, C., Viscomi, C., Moroni, A., Baruscotti, M. and DiFrancesco, D., 2003. Heteromeric HCN1-HCN4 channels: a comparison with native pacemaker channels from the rabbit sinoatrial node, J Physiol. 549, 347-59.

Ashcroft, F.M., 2001. Ion Channel and Disease, 1 ed. Academic Press, San Diego, CA.

Baig, S.M., Koschak, A., Lieb, A., Gebhart, M., Dafinger, C., Nurnberg, G., Ali, A., Ahmad, I., Sinnegger-Brauns, M.J., Brandt, N., Engel, J., Mangoni, M.E., Farooq, M., Khan, H.U., Nurnberg, P., Striessnig, J. and Bolz, H.J., 2011. Loss of Ca(v)1.3 (CACNA1D) function in a human channelopathy with bradycardia and congenital deafness, Nat Neurosci. 14, 77-84.

Baker, K., Warren, K.S., Yellen, G. and Fishman, M.C., 1997. Defective "pacemaker" current (Ih) in a zebrafish mutant with a slow heart rate, Proc Natl Acad Sci U S A. 94, 4554-9.

Barbuti, A., Terragni, B., Brioschi, C. and DiFrancesco, D., 2007. Localization of f-channels to caveolae mediates specific beta2-adrenergic receptor modulation of rate in sinoatrial myocytes, J Mol Cell Cardiol. 42, 71-8.

Baruscotti, M., Bucchi, A., Viscomi, C., Mandelli, G., Consalez, G., Gnecchi-Rusconi, T., Montano, N., Casali, K.R., Micheloni, S., Barbuti, A. and Difrancesco, D., 2011. Deep bradycardia and heart block caused by inducible cardiac-specific knockout of the pacemaker channel gene Hcn4, Proc Natl Acad Sci U S A. 108, 1705-10.

Baudot, M., Torre, E., Bidaud, I., Louradour, J., Torrente, A.G., Fossier, L., Talssi, L., Nargeot, J., Barrère-Lemaire, S., Mesirca, P. and Mangoni, M.E., 2020. Concomitant genetic ablation of

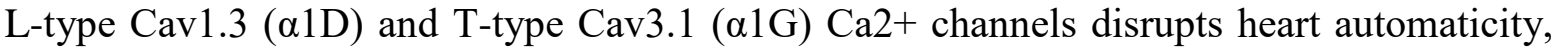
Scientific Reports. 10, 18906.

Bidaud, I., Chong, A.C.Y., Carcouet, A., Waard, S., Charpentier, F., Ronjat, M., Waard, M., Isbrandt, D., Wickman, K., Vincent, A., Mangoni, M.E. and Mesirca, P., 2020a. Inhibition of G proteingated $\mathrm{K}(+)$ channels by tertiapin-Q rescues sinus node dysfunction and atrioventricular conduction in mouse models of primary bradycardia, Sci Rep. 10, 9835.

Bidaud, I., D'Souza, A., Forte, G., Torre, E., Greuet, D., Thirard, S., Anderson, C., Chung You Chong, A., Torrente, A.G., Roussel, J., Wickman, K., Boyett, M.R., Mangoni, M.E. and Mesirca, P., 2020b. Genetic Ablation of G Protein-Gated Inwardly Rectifying K(+) Channels Prevents Training-Induced Sinus Bradycardia, Front Physiol. 11, 519382.

Bogdanov, K.Y., Vinogradova, T.M. and Lakatta, E.G., 2001. Sinoatrial nodal cell ryanodine receptor and $\mathrm{Na}(+)-\mathrm{Ca}(2+)$ exchanger: molecular partners in pacemaker regulation, Circ Res. 88, 12548.

Bround, M.J., Asghari, P., Wambolt, R.B., Bohunek, L., Smits, C., Philit, M., Kieffer, T.J., Lakatta, E.G., Boheler, K.R., Moore, E.D., Allard, M.F. and Johnson, J.D., 2012. Cardiac ryanodine receptors control heart rate and rhythmicity in adult mice, Cardiovasc Res. 96, 372-80.

Brown, H.F., DiFrancesco, D. and Noble, S.J., 1979. How does adrenaline accelerate the heart?, Nature. 280, 235-6. 
Bychkov, R., Juhaszova, M., Tsutsui, K., Coletta, C., Stern, M.D., Maltsev, V.A. and Lakatta, E.G., 2020. Synchronized Cardiac Impulses Emerge From Heterogeneous Local Calcium Signals Within and Among Cells of Pacemaker Tissue, JACC Clin Electrophysiol. 6, 907-931.

D'Souza, A., Bucchi, A., Johnsen, A.B., Logantha, S.J., Monfredi, O., Yanni, J., Prehar, S., Hart, G., Cartwright, E., Wisloff, U., Dobryznski, H., DiFrancesco, D., Morris, G.M. and Boyett, M.R., 2014. Exercise training reduces resting heart rate via downregulation of the funny channel HCN4, Nat Commun. 5, 3775.

D'Souza, A., Wang, Y., Anderson, C., Bucchi, A., Baruscotti, M., Olieslagers, S., Mesirca, P., Johnsen, A.B., Mastitskaya, S., Ni, H., Zhang, Y., Black, N., Cox, C., Wegner, S., BanoOtalora, B., Petit, C., Gill, E., Logantha, S., Dobrzynski, H., Ashton, N., Hart, G., Zhang, R., Zhang, H., Cartwright, E.J., Wisloff, U., Mangoni, M.E., da Costa Martins, P.A., Piggins, H.D., DiFrancesco, D. and Boyett, M.R., 2021. A circadian clock in the sinus node mediates day-night rhythms in Hcn4 and heart rate, Heart Rhythm. 18, 801-810.

DiFrancesco, D., 1986. Characterization of single pacemaker channels in cardiac sino-atrial node cells, Nature. 324, 470-3.

DiFrancesco, D., 2006. Serious workings of the funny current, Prog Biophys Mol Biol. 90, 13-25.

DiFrancesco, D., Ducouret, P. and Robinson, R.B., 1989. Muscarinic modulation of cardiac rate at low acetylcholine concentrations, Science. 243, 669-71.

DiFrancesco, D., Ferroni, A., Mazzanti, M. and Tromba, C., 1986. Properties of the hyperpolarizingactivated current (if) in cells isolated from the rabbit sino-atrial node, J Physiol. 377, 61-88.

DiFrancesco, D. and Mangoni, M., 1994. Modulation of single hyperpolarization-activated channels (i(f)) by cAMP in the rabbit sino-atrial node, J Physiol. 474, 473-82.

DiFrancesco, D. and Tortora, P., 1991. Direct activation of cardiac pacemaker channels by intracellular cyclic AMP, Nature. 351, 145-7.

Fenske, S., Hennis, K., Rotzer, R.D., Brox, V.F., Becirovic, E., Scharr, A., Gruner, C., Ziegler, T., Mehlfeld, V., Brennan, J., Efimov, I.R., Pauza, A.G., Moser, M., Wotjak, C.T., Kupatt, C., Gonner, R., Zhang, R., Zhang, H., Zong, X., Biel, M. and Wahl-Schott, C., 2020. cAMPdependent regulation of HCN4 controls the tonic entrainment process in sinoatrial node pacemaker cells, Nat Commun. 11, 5555.

Fenske, S., Krause, S.C., Hassan, S.I., Becirovic, E., Auer, F., Bernard, R., Kupatt, C., Lange, P., Ziegler, T., Wotjak, C.T., Zhang, H., Hammelmann, V., Paparizos, C., Biel, M. and WahlSchott, C.A., 2013. Sick sinus syndrome in HCN1-deficient mice, Circulation. 128, 2585-94.

Fenske, S., Mader, R., Scharr, A., Paparizos, C., Cao-Ehlker, X., Michalakis, S., Shaltiel, L., Weidinger, M., Stieber, J., Feil, S., Feil, R., Hofmann, F., Wahl-Schott, C. and Biel, M., 2011. HCN3 contributes to the ventricular action potential waveform in the murine heart, Circ Res. 109, 1015-23.

Gao, Z., Rasmussen, T.P., Li, Y., Kutschke, W., Koval, O.M., Wu, Y., Wu, Y., Hall, D.D., Joiner, M.L., Wu, X.Q., Swaminathan, P.D., Purohit, A., Zimmerman, K., Weiss, R.M., Philipson, K.D., Song, L.S., Hund, T.J. and Anderson, M.E., 2013. Genetic inhibition of Na+-Ca2+ exchanger current disables fight or flight sinoatrial node activity without affecting resting heart rate, Circ Res. 112, 309-17.

Gauss, R., Seifert, R. and Kaupp, U.B., 1998. Molecular identification of a hyperpolarizationactivated channel in sea urchin sperm, Nature. 393, 583-7.

Harzheim, D., Pfeiffer, K.H., Fabritz, L., Kremmer, E., Buch, T., Waisman, A., Kirchhof, P., Kaupp, U.B. and Seifert, R., 2008. Cardiac pacemaker function of HCN4 channels in mice is confined to embryonic development and requires cyclic AMP, Embo J. 27, 692-703.

Hennis, K., Biel, M., Wahl-Schott, C. and Fenske, S., 2021. Beyond pacemaking: HCN channels in sinoatrial node function, Prog Biophys Mol Biol.

Herrmann, S., Fabritz, L., Layh, B., Kirchhof, P. and Ludwig, A., 2011. Insights into sick sinus syndrome from an inducible mouse model, Cardiovasc Res. 90, 38-48. 
Herrmann, S., Stieber, J., Stockl, G., Hofmann, F. and Ludwig, A., 2007. HCN4 provides a 'depolarization reserve' and is not required for heart rate acceleration in mice, Embo J. 26, 4423-32.

Hoesl, E., Stieber, J., Herrmann, S., Feil, S., Tybl, E., Hofmann, F., Feil, R. and Ludwig, A., 2008. Tamoxifen-inducible gene deletion in the cardiac conduction system, J Mol Cell Cardiol. 45, 62-9.

Ishii, T.M., Takano, M., Xie, L.H., Noma, A. and Ohmori, H., 1999. Molecular characterization of the hyperpolarization-activated cation channel in rabbit heart sinoatrial node, Journal of Biological Chemistry. 274, 12835-9.

Kohajda, Z., Toth, N., Szlovak, J., Loewe, A., Bitay, G., Gazdag, P., Prorok, J., Jost, N., Levijoki, J., Pollesello, P., Papp, J.G., Varro, A. and Nagy, N., 2019. Novel $\mathrm{Na}(+) / \mathrm{Ca}(2+)$ Exchanger Inhibitor ORM-10962 Supports Coupled Function of Funny-Current and $\mathrm{Na}(+) / \mathrm{Ca}(2+)$ Exchanger in Pacemaking of Rabbit Sinus Node Tissue, Front Pharmacol. 10, 1632.

Lakatta, E.G., Maltsev, V.A. and Vinogradova, T.M., 2010. A coupled SYSTEM of intracellular $\mathrm{Ca} 2+$ clocks and surface membrane voltage clocks controls the timekeeping mechanism of the heart's pacemaker, Circ Res. 106, 659-73.

Ludwig, A., Budde, T., Stieber, J., Moosmang, S., Wahl, C., Holthoff, K., Langebartels, A., Wotjak, C., Munsch, T., Zong, X., Feil, S., Feil, R., Lancel, M., Chien, K.R., Konnerth, A., Pape, H.C., Biel, M. and Hofmann, F., 2003. Absence epilepsy and sinus dysrhythmia in mice lacking the pacemaker channel HCN2, Embo J. 22, 216-24.

Ludwig, A., Zong, X., Jeglitsch, M., Hofmann, F. and Biel, M., 1998. A family of hyperpolarizationactivated mammalian cation channels, Nature. 393, 587-91.

Lyashkov, A.E., Behar, J., Lakatta, E.G., Yaniv, Y. and Maltsev, V.A., 2018. Positive Feedback Mechanisms among Local Ca Releases, NCX, and ICaL Ignite Pacemaker Action Potentials, Biophys J. 114, 2024.

Mangoni, M.E., Couette, B., Bourinet, E., Platzer, J., Reimer, D., Striessnig, J. and Nargeot, J., 2003. Functional role of L-type Cav1.3 Ca2+ channels in cardiac pacemaker activity, Proc Natl Acad Sci U S A. 100, 5543-8.

Mangoni, M.E. and Nargeot, J., 2001. Properties of the hyperpolarization-activated current (I(f)) in isolated mouse sino-atrial cells, Cardiovasc Res. 52, 51-64.

Mangoni, M.E., Traboulsie, A., Leoni, A.L., Couette, B., Marger, L., Le Quang, K., Kupfer, E., Cohen-Solal, A., Vilar, J., Shin, H.S., Escande, D., Charpentier, F., Nargeot, J. and Lory, P., 2006. Bradycardia and slowing of the atrioventricular conduction in mice lacking CaV3.1/alpha1G T-type calcium channels, Circ Res. 98, 1422-30.

Marger, L., Mesirca, P., Alig, J., Torrente, A., Dubel, S., Engeland, B., Kanani, S., Fontanaud, P., Striessnig, J., Shin, H.S., Isbrandt, D., Ehmke, H., Nargeot, J. and Mangoni, M.E., 2011a. Functional roles of $\mathrm{Ca}(\mathrm{v}) 1.3, \mathrm{Ca}(\mathrm{v}) 3.1$ and $\mathrm{HCN}$ channels in automaticity of mouse atrioventricular cells: insights into the atrioventricular pacemaker mechanism, Channels (Austin). 5, 251-61.

Marger, L., Mesirca, P., Alig, J., Torrente, A., Dubel, S., Engeland, B., Kanani, S., Fontanaud, P., Striessnig, J., Shin, H.S., Isbrandt, D., Ehmke, H., Nargeot, J. and Mangoni, M.E., 2011b. Pacemaker activity and ionic currents in mouse atrioventricular node cells, Channels (Austin). 5, 241-50.

Marionneau, C., Couette, B., Liu, J., Li, H., Mangoni, M.E., Nargeot, J., Lei, M., Escande, D. and Demolombe, S., 2005. Specific pattern of ionic channel gene expression associated with pacemaker activity in the mouse heart, J Physiol. 562, 223-34.

Mesirca, P., Alig, J., Torrente, A.G., Muller, J.C., Marger, L., Rollin, A., Marquilly, C., Vincent, A., Dubel, S., Bidaud, I., Fernandez, A., Seniuk, A., Engeland, B., Singh, J., Miquerol, L., Ehmke, H., Eschenhagen, T., Nargeot, J., Wickman, K., Isbrandt, D. and Mangoni, M.E., 2014. Cardiac arrhythmia induced by genetic silencing of 'funny' (f) channels is rescued by GIRK4 inactivation, Nat Commun. 5, 4664. 
Mesirca, P., Bidaud, I., Briec, F., Evain, S., Torrente, A.G., Le Quang, K., Leoni, A.L., Baudot, M., Marger, L., Chung You Chong, A., Nargeot, J., Striessnig, J., Wickman, K., Charpentier, F. and Mangoni, M.E., 2016a. G protein-gated IKACh channels as therapeutic targets for treatment of sick sinus syndrome and heart block, Proc Natl Acad Sci U S A. 113, E932-41.

Mesirca, P., Bidaud, I. and Mangoni, M.E., 2016b. Rescuing cardiac automaticity in L-type Cav1.3 channelopathies and beyond, J Physiol. 594, 5869-5879.

Mesirca, P., Fedorov, V.V., Hund, T.J., Torrente, A.G., Bidaud, I., Mohler, P.J. and Mangoni, M.E., 2021a. Pharmacologic Approach to Sinoatrial Node Dysfunction, Annu Rev Pharmacol Toxicol. 61, 757-778.

Mesirca, P., Marger, L., Toyoda, F., Rizzetto, R., Audoubert, M., Dubel, S., Torrente, A.G., Difrancesco, M.L., Muller, J.C., Leoni, A.L., Couette, B., Nargeot, J., Clapham, D.E., Wickman, K. and Mangoni, M.E., 2013. The G-protein-gated K+ channel, IKACh, is required for regulation of pacemaker activity and recovery of resting heart rate after sympathetic stimulation, J Gen Physiol. 142, 113-26.

Mesirca, P., Nakao, S., Nissen, S.D., Forte, G., Anderson, C., Trussell, T., Li, J., Cox, C., Zi, M., Logantha, S.J.R., Yaar, S., Carstensen, H., Bidaud, I., Stuart, L., Soattin, L., Morris, G.M., da Costa Martins, P.A., Cartwright, E.J., Oceandy, D., Mangoni, M.E., Jespersen, T., Buhl, R., Dobrzynski, H., Boyett, M.R. and D'Souza, A., 2021b. Intrinsic Electrical Remodeling Underlies Atrioventricular Block in Athletes, Circ Res.

Milano, A., Vermeer, A.M., Lodder, E.M., Barc, J., Verkerk, A.O., Postma, A.V., van der Bilt, I.A., Baars, M.J., van Haelst, P.L., Caliskan, K., Hoedemaekers, Y.M., Le Scouarnec, S., Redon, R., Pinto, Y.M., Christiaans, I., Wilde, A.A. and Bezzina, C.R., 2014. HCN4 mutations in multiple families with bradycardia and left ventricular noncompaction cardiomyopathy, J Am Coll Cardiol. 64, 745-56.

Miquerol, L., Meysen, S., Mangoni, M., Bois, P., van Rijen, H.V., Abran, P., Jongsma, H., Nargeot, J. and Gros, D., 2004. Architectural and functional asymmetry of the His-Purkinje system of the murine heart, Cardiovasc Res. 63, 77-86.

Moosmang, S., Stieber, J., Zong, X., Biel, M., Hofmann, F. and Ludwig, A., 2001. Cellular expression and functional characterization of four hyperpolarization-activated pacemaker channels in cardiac and neuronal tissues, Eur J Biochem. 268, 1646-52.

Moroni, A., Gorza, L., Beltrame, M., Gravante, B., Vaccari, T., Bianchi, M.E., Altomare, C., Longhi, R., Heurteaux, C., Vitadello, M., Malgaroli, A. and DiFrancesco, D., 2001. Hyperpolarization-activated cyclic nucleotide-gated channel 1 is a molecular determinant of the cardiac pacemaker current I(f), J Biol Chem. 276, 29233-41.

Neco, P., Torrente, A.G., Mesirca, P., Zorio, E., Liu, N., Priori, S.G., Napolitano, C., Richard, S., Benitah, J.P., Mangoni, M.E. and Gomez, A.M., 2012. Paradoxical effect of increased diastolic $\mathrm{Ca} 2+$ release and decreased sinoatrial node activity in a mouse model of catecholaminergic polymorphic ventricular tachycardia, Circulation. 126, 392-401.

Noble, D., 2020. The surprising heart revisited: an early history of the funny current with modern lessons, Prog Biophys Mol Biol.

Noble, D., Denyer, J.C., Brown, H.F. and DiFrancesco, D., 1992. Reciprocal role of the inward currents ib, Na and i(f) in controlling and stabilizing pacemaker frequency of rabbit sino-atrial node cells, Proc R Soc Lond B Biol Sci. 250, 199-207.

Noda, M., Ikeda, T., Suzuki, H., Takeshima, H., Takahashi, T., Kuno, M. and Numa, S., 1986. Expression of functional sodium channels from cloned cDNA, Nature. 322, 826-8.

Noma, A. and Irisawa, H., 1976. Membrane currents in the rabbit sinoatrial node cell as studied by the double microelectrode method, Pflugers Arch. 364, 45-52.

Sah, R., Mesirca, P., Mason, X., Gibson, W., Bates-Withers, C., Van den Boogert, M., Chaudhuri, D., Pu, W.T., Mangoni, M.E. and Clapham, D.E., 2013a. Timing of myocardial trpm7 deletion during cardiogenesis variably disrupts adult ventricular function, conduction, and repolarization, Circulation. 128, 101-14. 
Sah, R., Mesirca, P., Van den Boogert, M., Rosen, J., Mably, J., Mangoni, M.E. and Clapham, D.E., 2013b. Ion channel-kinase TRPM7 is required for maintaining cardiac automaticity, Proc Natl Acad Sci U S A. 110, E3037-46.

Santoro, B., Liu, D.T., Yao, H., Bartsch, D., Kandel, E.R., Siegelbaum, S.A. and Tibbs, G.R., 1998. Identification of a gene encoding a hyperpolarization-activated pacemaker channel of brain, Cell. 93, 717-29.

Schulze-Bahr, E., Neu, A., Friederich, P., Kaupp, U.B., Breithardt, G., Pongs, O. and Isbrandt, D., 2003. Pacemaker channel dysfunction in a patient with sinus node disease, J Clin Invest. 111, 1537-45.

Schweizer, P.A., Duhme, N., Thomas, D., Becker, R., Zehelein, J., Draguhn, A., Bruehl, C., Katus, H.A. and Koenen, M., 2010. cAMP sensitivity of HCN pacemaker channels determines basal heart rate but is not critical for autonomic rate control, Circ Arrhythm Electrophysiol. 3, 54252.

Schweizer, P.A., Schroter, J., Greiner, S., Haas, J., Yampolsky, P., Mereles, D., Buss, S.J., Seyler, C., Bruehl, C., Draguhn, A., Koenen, M., Meder, B., Katus, H.A. and Thomas, D., 2014. The symptom complex of familial sinus node dysfunction and myocardial noncompaction is associated with mutations in the HCN4 channel, J Am Coll Cardiol. 64, 757-67.

Shan, J., Kushnir, A., Betzenhauser, M.J., Reiken, S., Li, J., Lehnart, S.E., Lindegger, N., Mongillo, M., Mohler, P.J. and Marks, A.R., 2010. Phosphorylation of the ryanodine receptor mediates the cardiac fight or flight response in mice, J Clin Invest. 120, 4388-98.

Shi, W., Wymore, R., Yu, H., Wu, J., Wymore, R.T., Pan, Z., Robinson, R.B., Dixon, J.E., McKinnon, D. and Cohen, I.S., 1999. Distribution and prevalence of hyperpolarization-activated cation channel (HCN) mRNA expression in cardiac tissues, Circ Res. 85, e1-6.

Stainier, D.Y., Fouquet, B., Chen, J.N., Warren, K.S., Weinstein, B.M., Meiler, S.E., Mohideen, M.A., Neuhauss, S.C., Solnica-Krezel, L., Schier, A.F., Zwartkruis, F., Stemple, D.L., Malicki, J., Driever, W. and Fishman, M.C., 1996. Mutations affecting the formation and function of the cardiovascular system in the zebrafish embryo, Development. 123, 285-92.

Stieber, J., Herrmann, S., Feil, S., Loster, J., Feil, R., Biel, M., Hofmann, F. and Ludwig, A., 2003a. The hyperpolarization-activated channel HCN4 is required for the generation of pacemaker action potentials in the embryonic heart, Proc Natl Acad Sci U S A. 100, 15235-40.

Stieber, J., Thomer, A., Much, B., Schneider, A., Biel, M. and Hofmann, F., 2003b. Molecular basis for the different activation kinetics of the pacemaker channels HCN2 and HCN4, J Biol Chem. 278, 33672-80.

Torrente, A.G., Mesirca, P., Bidaud, I. and Mangoni, M.E., 2020. Channelopathies of voltage-gated L-type Cav1.3/alpha1D and T-type Cav3.1/alpha1G Ca(2+) channels in dysfunction of heart automaticity, Pflugers Arch. 472, 817-830.

Torrente, A.G., Mesirca, P., Neco, P., Rizzetto, R., Dubel, S., Barrere, C., Sinegger-Brauns, M., Striessnig, J., Richard, S., Nargeot, J., Gomez, A.M. and Mangoni, M.E., 2016. L-type Cav1.3 channels regulate ryanodine receptor-dependent $\mathrm{Ca} 2+$ release during sino-atrial node pacemaker activity, Cardiovasc Res. 109, 451-61.

Torrente, A.G., Zhang, R., Zaini, A., Giani, J.F., Kang, J., Lamp, S.T., Philipson, K.D. and Goldhaber, J.I., 2015. Burst pacemaker activity of the sinoatrial node in sodium-calcium exchanger knockout mice, Proc Natl Acad Sci U S A. 112, 9769-74.

Toyoda, F., Mesirca, P., Dubel, S., Ding, W.G., Striessnig, J., Mangoni, M.E. and Matsuura, H., 2017. CaV1.3 L-type Ca2+ channel contributes to the heartbeat by generating a dihydropyridinesensitive persistent $\mathrm{Na}+$ current, Sci Rep. 7, 7869.

Vaccari, T., Moroni, A., Rocchi, M., Gorza, L., Bianchi, M.E., Beltrame, M. and DiFrancesco, D., 1999. The human gene coding for HCN2, a pacemaker channel of the heart, Biochim Biophys Acta. 1446, 419-25. 
Verheijck, E.E., van Kempen, M.J., Veereschild, M., Lurvink, J., Jongsma, H.J. and Bouman, L.N., 2001. Electrophysiological features of the mouse sinoatrial node in relation to connexin distribution, Cardiovasc Res. 52, 40-50.

Viatchenko-Karpinski, S., Fleischmann, B.K., Liu, Q., Sauer, H., Gryshchenko, O., Ji, G.J. and Hescheler, J., 1999. Intracellular Ca2+ oscillations drive spontaneous contractions in cardiomyocytes during early development, Proc Natl Acad Sci U S A. 96, 8259-64.

Vinogradova, T.M., Bogdanov, K.Y. and Lakatta, E.G., 2002. beta-Adrenergic stimulation modulates ryanodine receptor $\mathrm{Ca}(2+)$ release during diastolic depolarization to accelerate pacemaker activity in rabbit sinoatrial nodal cells, Circ Res. 90, 73-9.

Wallace, M.J., El Refaey, M., Mesirca, P., Hund, T.J., Mangoni, M.E. and Mohler, P.J., 2021. Genetic Complexity of Sinoatrial Node Dysfunction, Front Genet. 12, 654925.

Wang, Y.Y., Mesirca, P., Marques-Sule, E., Zahradnikova, A., Jr., Villejoubert, O., D'Ocon, P., Ruiz, C., Domingo, D., Zorio, E., Mangoni, M.E., Benitah, J.P. and Gomez, A.M., 2017. RyR2R420Q catecholaminergic polymorphic ventricular tachycardia mutation induces bradycardia by disturbing the coupled clock pacemaker mechanism, JCI Insight. 2.

Warren, K.S., Baker, K. and Fishman, M.C., 2001. The slow mo mutation reduces pacemaker current and heart rate in adult zebrafish, Am J Physiol Heart Circ Physiol. 281, H1711-9.

Wickman, K., Nemec, J., Gendler, S.J. and Clapham, D.E., 1998. Abnormal heart rate regulation in GIRK4 knockout mice, Neuron. 20, 103-14.

Wickman, K., Seldin, M.F., Gendler, S.J. and Clapham, D.E., 1997. Partial structure, chromosome localization, and expression of the mouse Girk4 gene, Genomics. 40, 395-401.

Yue, X., Hazan, A., Lotteau, S., Zhang, R., Torrente, A.G., Philipson, K.D., Ottolia, M. and Goldhaber, J.I., 2020. Na/Ca exchange in the atrium: Role in sinoatrial node pacemaking and excitation-contraction coupling, Cell Calcium. 87, 102167. 
Figure 1. Representative traces, from the first recordings in 2001, of the principal ionic currents expressed in isolated mouse sinoatrial node myocytes. Adapted from Mangoni et al. Prog. Biophys. Mol. Biol. 90 (2006) 38-63.

Figure 2. Conditional hHCN4-573X expressing double transgenic (HCN4-CNBD) mice. (A) Schematic representation of single HCN subunits indicating the position of the mutation in the cyclic nucleotide-binding domain (CNBD) linker. (B) Representative scheme of the Tet-Off system. $\alpha \mathrm{MHC}$, alpha-myosin heavy-chain; tTA, Tet-Off system transactivator; Tre, tetracycline-responsive element; DOX, doxycycline. (C) Sample traces of $\mathrm{I}_{\mathrm{f}}$ recorded in isolated sinoatrial node myocytes from control (Cont, left panel) and mutant (HCN4-CNBD, right panel) animals together with current to voltage (IV) relationships under tyrode (Tyr, black symbols), or isoproterenol (ISO $100 \mathrm{nM}$, red symbols) perfusion. (D) Representative examples of ECG traces recorded in control (left) and mutant animals on DOX (center), or water (right), at low (top) and high (bottom) levels of spontaneous home cage activity. Adapted from Alig et al. PNAS 106 (2009) 12189-12194.

Figure 3. Conditional hHCN4-AYA transgenic mice. (A) Representative scheme of the Tet-Off system. $\alpha \mathrm{MHC}$, alpha-myosin heavy-chain; tTA, Tet-Off system transactivator; Tre, tetracyclineresponsive element; DOX, doxycycline. (B) Representative If traces and action potential recordings in isolated sinoatrial node myocytes from control (Cont, left panel) and mutant (HCN4-AYA, right panel) animals. Insets: Action potential examples recorded in tyrode solution (black traces) or under isoproterenol (100 $\mathrm{nM}$ ) perfusion (gray traces). Red circle indicates a delayed afterdepolarization (DAD). Cycle length, CL. (C) Representative examples of ECG showing different hallmarks of heart arrhythmias (blue arrows) recorded from mutant mice. Adapted from Mesirca et al. Nat Commun (2014) 5:4664. 

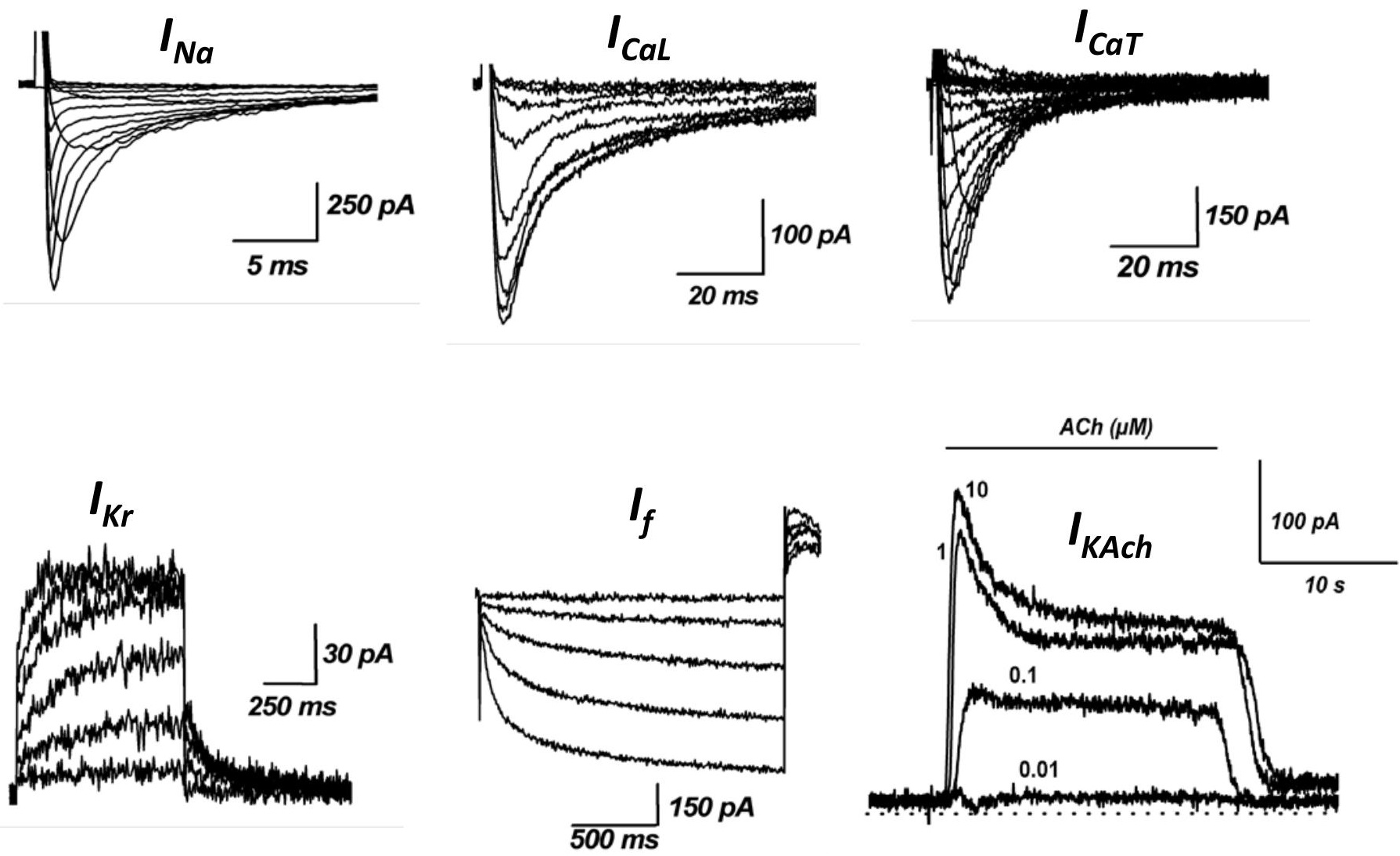

Figure 1 
A

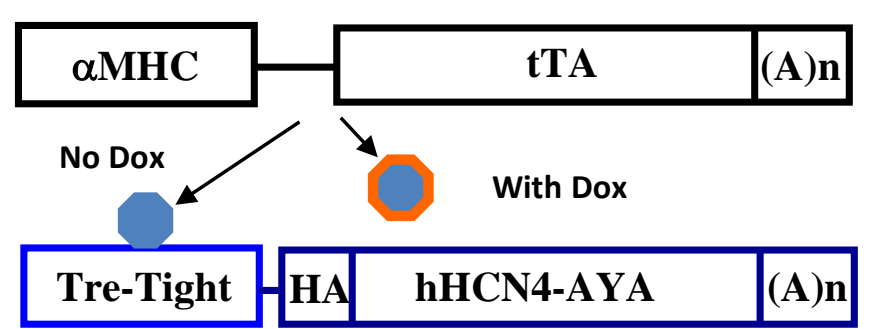

B

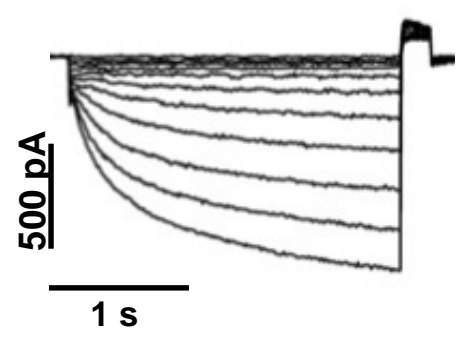

Cont

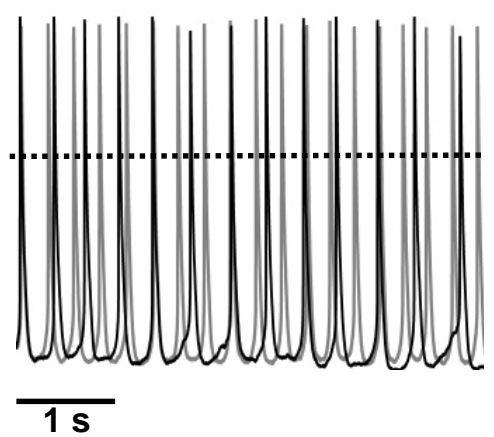

C Sinus Pause

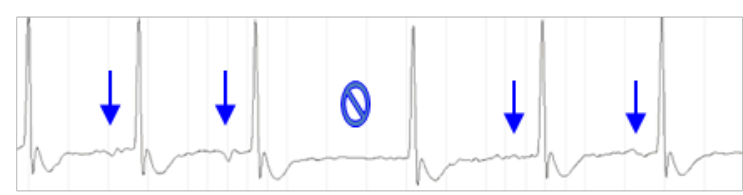

Ventricular Tachycardia

$$
\downarrow \downarrow \downarrow \downarrow \downarrow
$$

\section{HCN4-AYA}

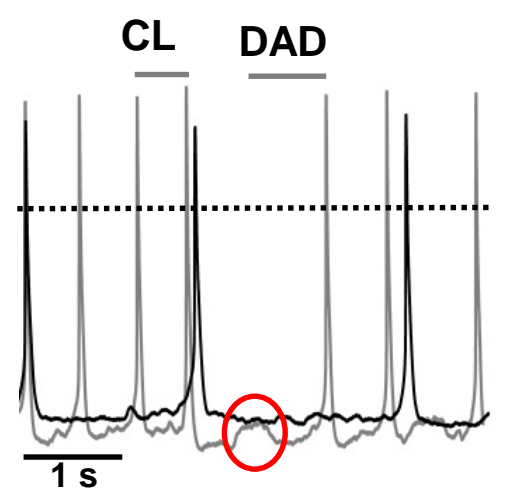

Atrial Fibrillation

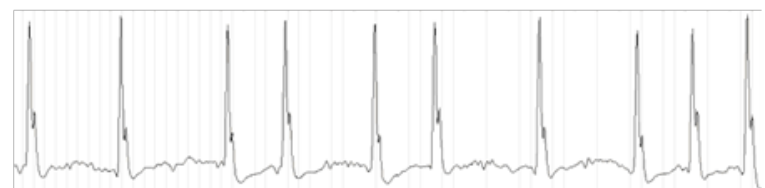

Atrio-ventricular block

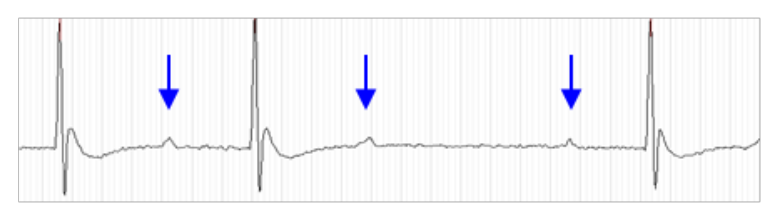


A

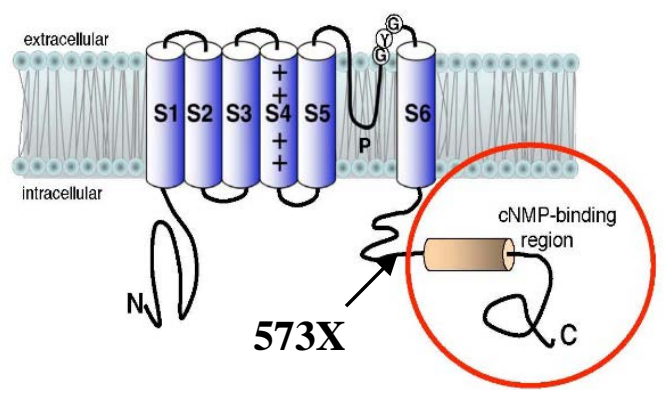

C

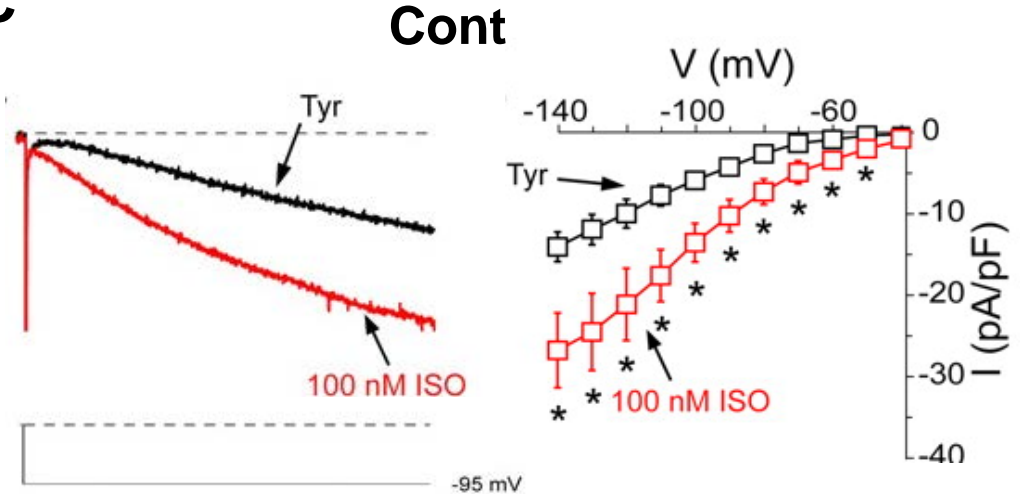

D

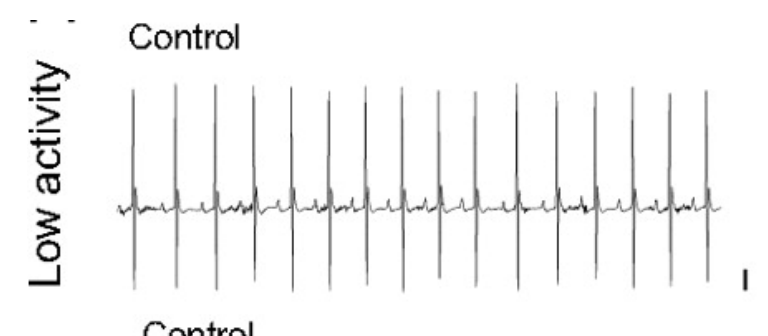

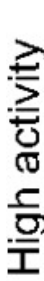

Control

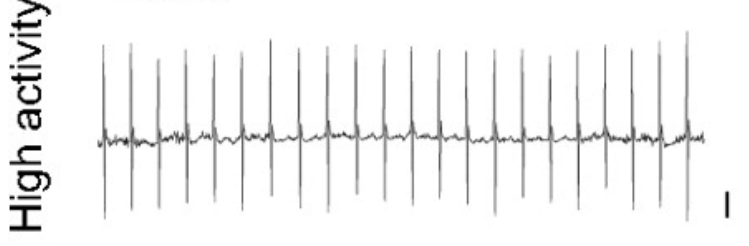

B

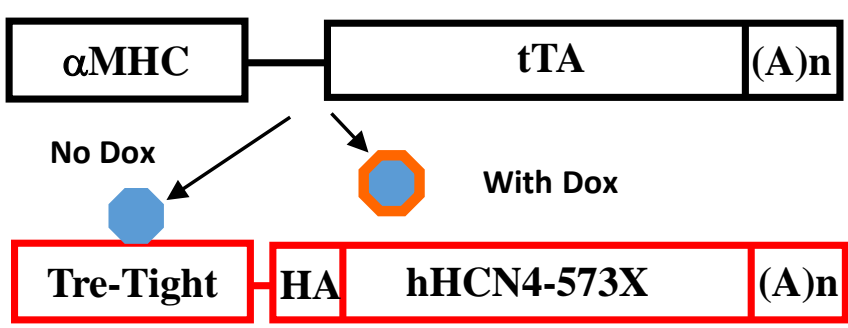

HCN4-CNBD

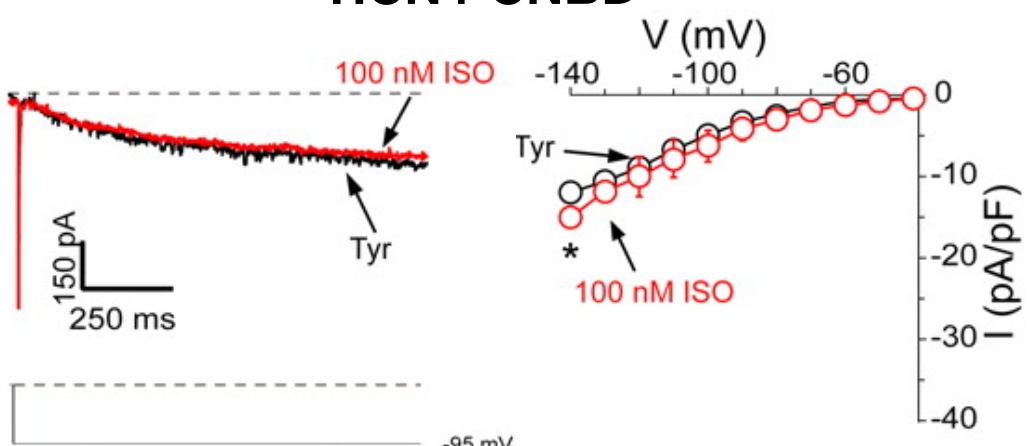

DW mutant on DOX

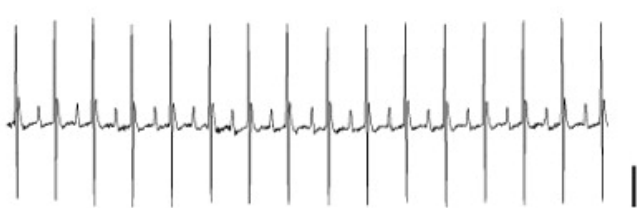

DW mutant on DOX

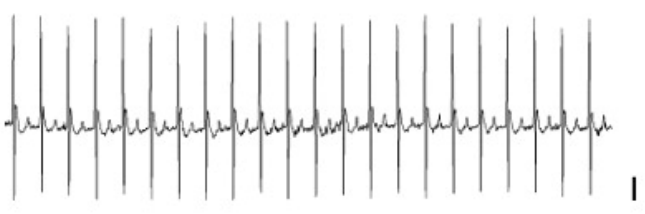

DW mutant on water

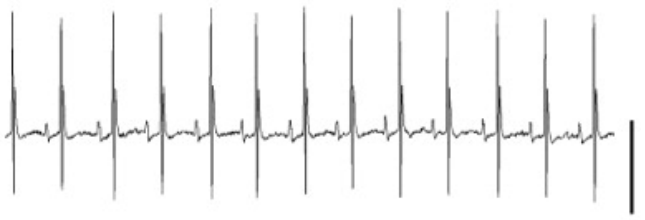

DW mutant on water

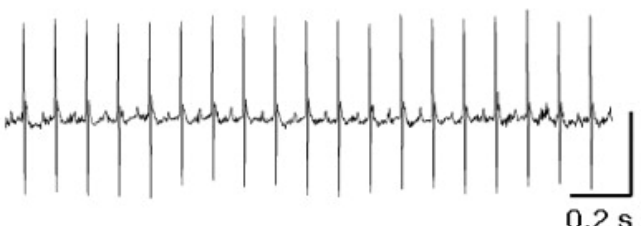

Figure 2 